\title{
Hand held lasers, a hazard to aircraft: How do we address this?
}

\section{K. Barat}

K. Barat, "Hand held lasers, a hazard to aircraft: How do we address this?," Proc. SPIE 9793, Education and Training in Optics and Photonics: ETOP 2015, 97931P (8 October 2015); doi: 10.1117/12.2223126

SPIE Event: Education and Training in Optics and Photonics: ETOP 2015, 2015, Bordeaux, France 


\title{
Hand Held Lasers, a hazard to aircraft, how do we address this?
}

K. Barat, Laser Safety Solutions, 42179 W. Santa Fe St, Maricopa, Arizona, 85138 USA

\begin{abstract}
The availability of hand held lasers, commonly termed "laser pointers" is easy and wide spread, through commercial web sites and brick \& mortar stores. The output of these hand held devices ranges from 1-5 milliWatts (mW) the legal laser pointer output limit, to $5000 \mathrm{~mW}$ (5Watts!!!). This is thousand times the maximum limit for pointers. Sadly the abuse of these devices is also wide spread. Over the last few years over 3000 aircraft are exposed to laser hits per year. While these aircraft exposures are of no danger to the aircraft frame but they can cause pilot distractions with the potential to cause a serve accident. The presentation will discuss the problem review visual effects, the regulatory response and how educators need to be aware of the problem and can take steps to educate students in the hope of having an effect on the
\end{abstract}

Keywords: Laser pointer, hand held laser, aircraft, pilots illumination

\section{INTRODUCTION}

Up in the sky, it's a bird, it's a plane, no, it's a laser beam! Aircraft illumination by handheld lasers has become a worldwide problem. To such a level that in the United States the FBI offers a \$10,000 reward for information that leads to a conviction of such individuals.

First a quick distinction: Laser Pointer is a hand held visible laser device that emits no more than $5 \mathrm{~mW}$ as a continuous wave beam. A hand held laser is any laser device that can be held by hand (portable) and whose visible output is greater than $5 \mathrm{~mW}$. Today one can buy a hand held laser from the internet from 10-5000 $\mathrm{mW}$ that is $5 \mathrm{Watts}$ in a handheld device.

The availability of hand held lasers, commonly termed "laser pointers" is easy and wide spread, through commercial web sites and brick \& mortar stores. The output of these hand held devices ranges from 1-5 milliWatts $(\mathrm{mW})$ the legal laser pointer output limit, to $5000 \mathrm{~mW}$. This is thousand times the maximum limit for pointers. Sadly the abuse of these devices is also wide spread. Over the last few years over 2000 aircraft are exposed to laser hits per year. While these aircraft exposures are of no danger to the aircraft frame but they can cause pilot distractions with the potential to cause a serve accident. Educators need to be aware of the problem and can take steps to educate students in the hope of having an effect on the problem.

The goal of this presentation is to raise the reader's awareness of this problem and it is a problem. It is the obligation of those of us in the optics and photonics industry to speak up about this issues. If you know someone with a pointer or hand held laser educate them. The bottom line is individuals who illuminate aircraft, helicopters are not only breaking the law but putting people at risk.

Since we are talking about green light at night or low light conditions, not much light is required to illicit these effects. All of these are possible and have been reported. How many events are we talking about? During 2014, there were 3,894 laser incidents reported to the U.S. Federal Aviation Administration, 3,960 in 2013. The FAA has a free downloadable video on its web site on the issue and explains how pilots should deal with it. This includes helicopter pilots, which fly considerable lower altitudes, 1200 feet or closer to the ground. The video makes a great safety meeting presentation. It is a violation of US Federal law as well as many States with similar laws against the exposing planes or helicopters to laser radiation. What is the purpose of such acts, hard to say, maybe it is to see if they can hit the plane, simple mischief, stupidity or terrorist intent, and the answer lies with each individual.

Ken Barat, Laser Safety Solutions, lasersafetysolutions@gmail.com 952-698-5661

Education and Training in Optics and Photonics: ETOP 2015, edited by Eric Cormier, Laurent Sarger Proc. of SPIE Vol. 9793, 97931P · (c) 2015 SPIE, IEEE, OSA, ICO · doi: 10.1117/12.2223126 
The danger of illuminating a cockpit is the distraction to the pilot. Consider you are traveling down the highway at a rapid speed and now a bright light hits you. While your vision is obscured you tend to stay straight and maybe slow down until you can see the road again, hoping there is not a curve ahead. Now consider you are landing or taking off, the light hits you, runway lights are blurred. Your reaction might be to divert your path, or turnover to the other pilot if you have one. Changing your flight path which not only could endanger your plane but any others in the zone. Helicopter diverting its course could hit a nearby power line or building.

The hazard from these lasers is not to the aircraft frame, but to the pilot's distraction. The distance where these lasers present a retinal hazard seems impractical for the operator to be present. While the intensity needed to distract a pilot is extremely low (nanowatt range). The effects defined below is from laser pointers and hand held lasers. Let's define terms:

Glare - Obscuration of an object in a person's field of vision due to a bright light source near the same line-of sight (e.g., oncoming car headlights).

Flash blindness - A visual interference effect that persists after the source of illumination has ceased.

Afterimage - A reverse contrast shadow image left in the visual field after an exposure to a bright light that may persist for several minutes.

The overwhelming number of hand held laser are manufactured in Asia. Random testing of units has shown questionable quality control, outputs vastly different from indicated and failure to include IR filters for Green lasers. The most popular laser unit involved in these events are the green $532 \mathrm{~nm}$ laser. Which is a great deal of technology in one's hand. Consider you are holding a frequency doubled Nd:YAG laser system: A $808 \mathrm{~nm}$ diode pump, Nd:YAG (or Nd:YLF) crystal, generating a $1064 \mathrm{~nm}$ beam going through a nonlinear crystal, yielding a bright $532 \mathrm{~nm}$ beam and focusing optics. Hoping an infrared filter has been put in place to block the residual $808 \mathrm{~nm}$ and $1064 \mathrm{~nm}$ beams from exiting.

A common question is can I really hit the cockpit? The answer is yes. To the user the beam may seem to end at 1200 feet from its point of origin. The beam that is visible to the user is scattered light from dust and other particles in the air. This layer of dust and aerosols sits only close the ground, and once the beam exits that layer (called a boundary layer), it continues on. The truth is the beam continues on until it hits something. For example a $5 \mathrm{~mW}$ laser pointer is a distraction hazard to pilots over two miles away. Some higher output ones can cause serious glare (the pilot can't see past the light) two miles away, while the distraction hazard is 22 miles. The beam will not be consistent on target, but random flashing is commonly reported. There are uses for laser pointers, backyard astronomers use for sighting stars, instructors, pointer out items at heights but striking aircraft or individuals is not a legitimate use.

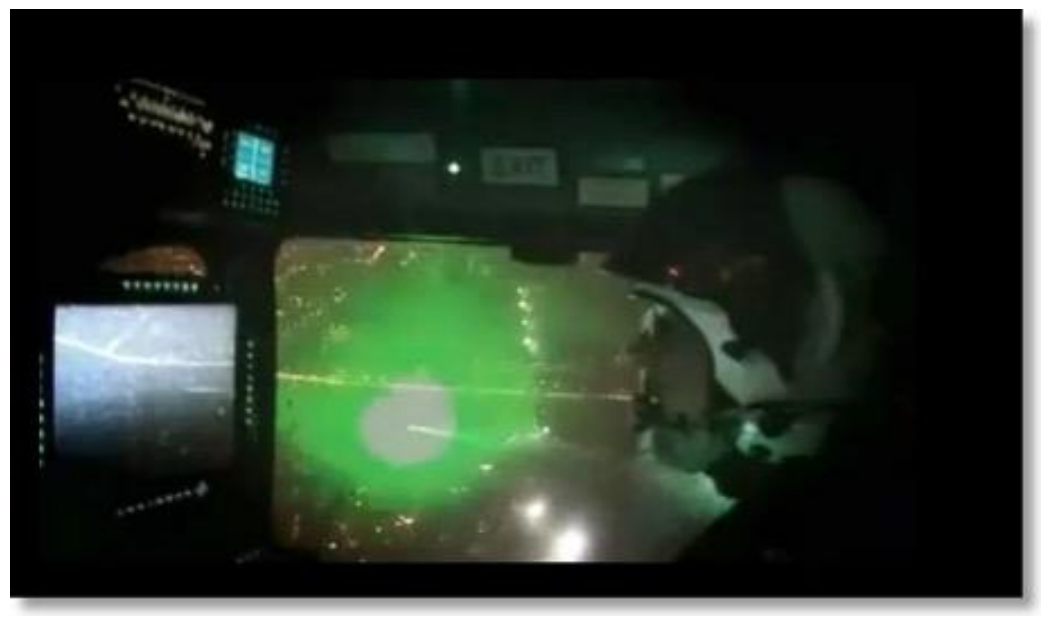

Figure 1.Inside view of cockpit during illumination by a hand held laser

In 2013, in the United Satesm, 74 incidents where law enforcement action was taken. 11 Prosecutions - 2 Federal, 1 State Conviction. Federal Sentences range from 1 year probation to 14 years in Federal Prison. 


\section{How about eyewear?}

Why not supply pilots with laser protective eyewear? We are aware of four brands at this time (June 2013): Laser-Gard eyewear from Sperian/Honeywell, LaserShields eyewear from NoIR Laser Co., Laser Armor eyewear from Night Flight Concepts, and LaseReflect Aviator eyewear from Iridian Spectral Technologies.

Pilots should NOT rely on ordinary sunglasses or common "blue blocker" type glasses. Using sunglasses at dusk, night and dawn (when almost all laser incidents occur) could be unsafe. Blue blocker glasses have an effect on many different colors of blue and green. This may adversely affect how cockpit instruments and airport lights are perceived.

While eyewear designed for pilots can be useful, they do not block out all visible laser wavelengths and pilots may feel that the chance of being illuminated are so small, they would rather not wear them. It is the same as with doctors refusing to wear laser protective eyewear in the operating room during laser procedures. Pilot's should know what steps to take if their cockpit is illuminated. Which are turn up cockpit lights, turn on auto pilot, look away and do not rub their eyes (potential to scratch ones cornea).

\section{Testing of hand held units}

Using a moderately low-cost apparatus designed to quickly and accurately measure the properties of handheld laser devices, National Institute of Standards and Technology (NIST), United States researchers tested 122 laser pointers and found that nearly 90 percent of green pointers and about 44 percent of red pointers tested were out of compliance with federal safety regulations. The NIST test apparatus was designed so that it can be replicated easily by other institutions.

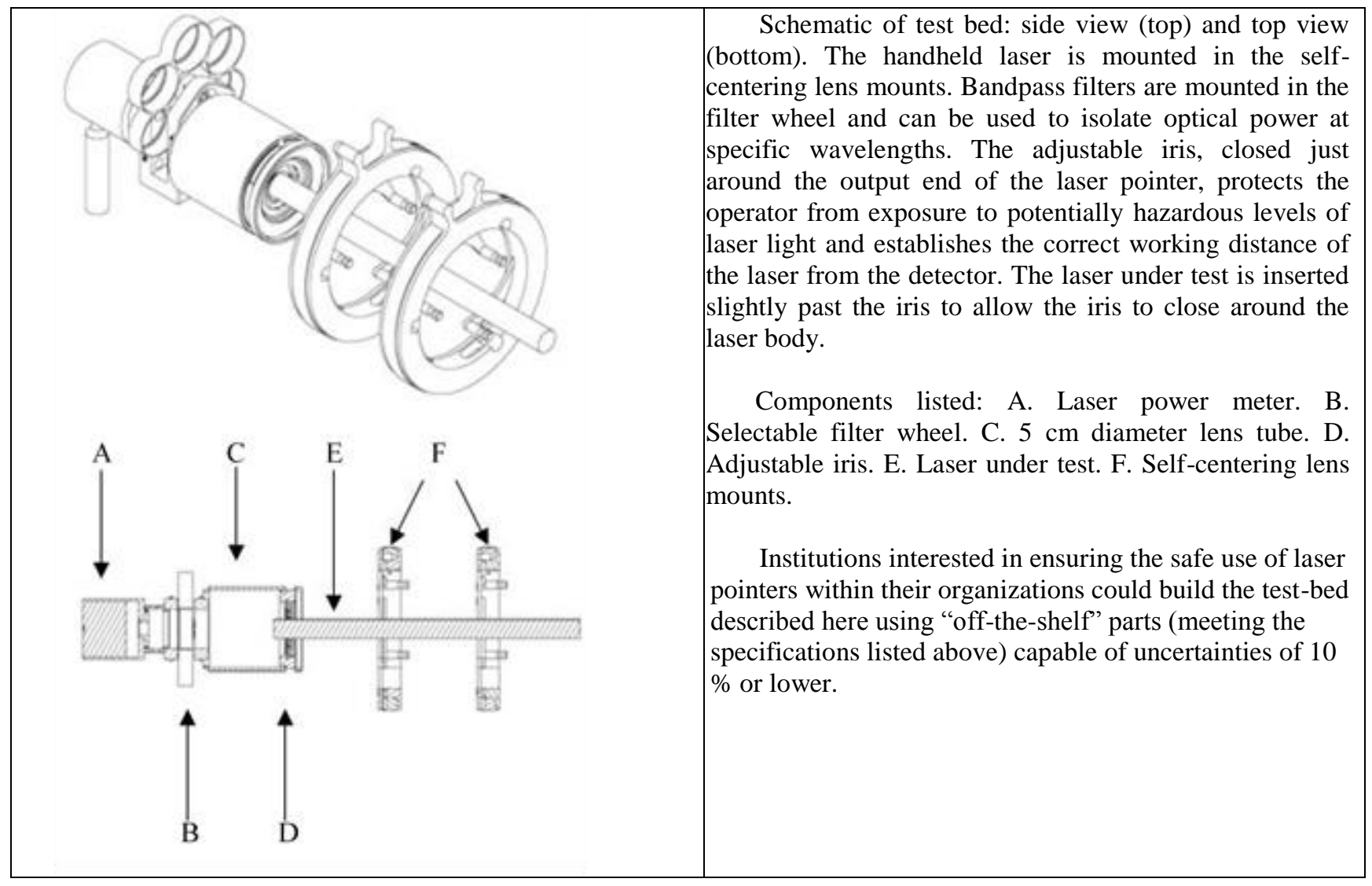




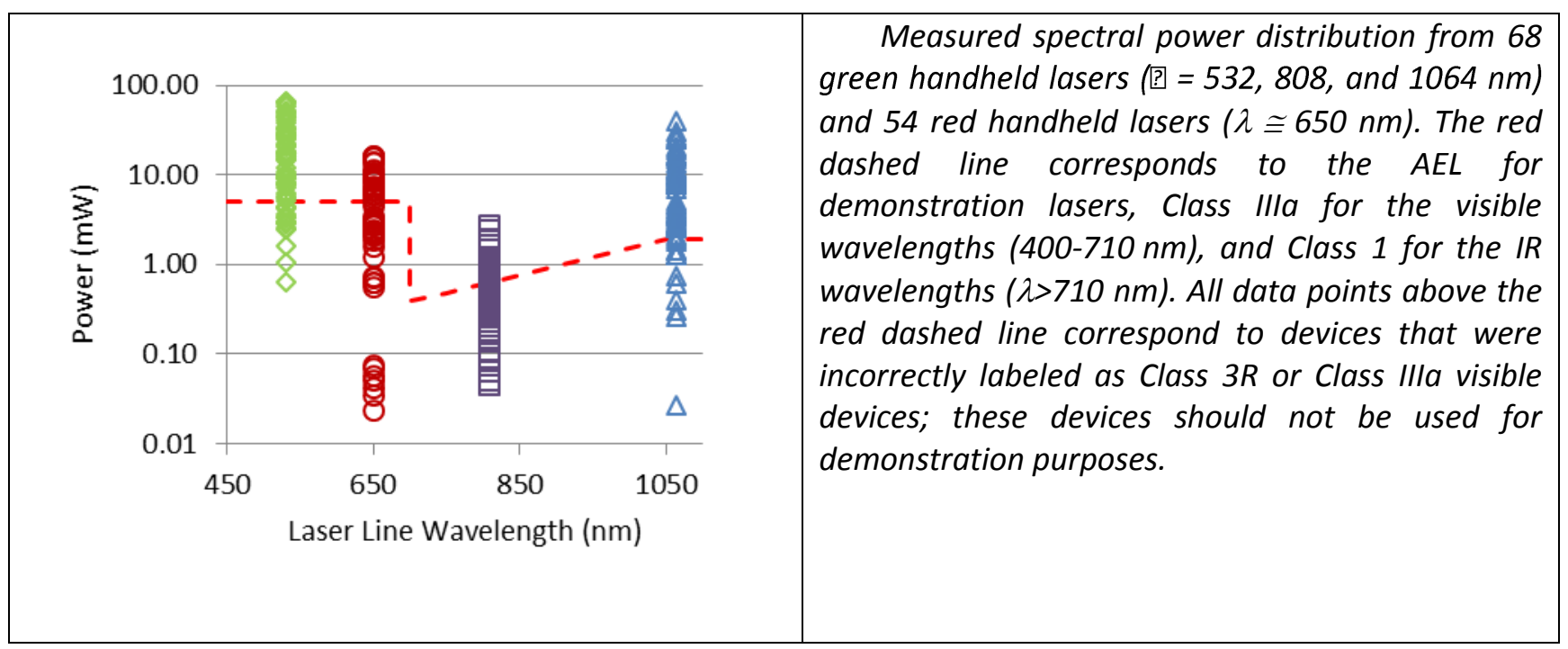

\section{Regulatory response in the United States}

- $\quad$ U.S. NATIONAL LAWS

- U.S. FDA/CDRH: 21 CFR 1040.10/11

- U.S.: Illegal to aim laser pointer beams at aircraft or their flight path

- U.S. FDA/CDRH recommends aircraft/vehicle caution label

- US: FDA proposes changes to Federal Laser Performance Standard

- US: (For reference) Radiation Control for Health and Safety Act of 1968

- $\quad$ STATE AND LOCAL LAWS

- ARIZONA: Aiming a laser pointer at a peace officer or an occupied aircraft

- ARKANSAS: Law enforcement; minors

- CALIFORNIA: Laser regulations

- FLORIDA: Law enforcement and illuminating vehicles

- FLORIDA: City of Leesburg bans laser harassment in 1999

- GEORGIA: Illegal to aim at police, aircraft (proposed)

- HAWAII: Illegal for under-18-year-olds to possess laser pointers

- ILLINOIS: All Class 3B and 4 lasers must be registered

- ILLINOIS: Criminalize discharge into cockpits

- ILLINOIS, statewide: General requirements

- ILLINOIS, county of Champaign: Possession and use

- ILLINOIS, village of Westchester: City bans possession by minors

- INDIANA: Laser pointer laws

- LOUISIANA, illegal to intentionally aim laser light at aircraft

- LOUISIANA, city of Baton Rouge

- MARYLAND, statewide: Misdemeanor to knowingly aim at aircraft

- MARYLAND, town of Ocean City (2014): Ban on sales and possession; restriction on use

- MARYLAND, town of Ocean City (2010): Ban and restriction on some uses, sales

- MARYLAND, town of Ocean City (1998): Harassment prohibited

- MICHIGAN, city of Dearborn: Unlawful to harass 
- MINNESOTA: Crime to aim laser into cockpit

- NEW JERSEY, town of Ocean City (2011): Ban on laser pointer sales and possession

- NEW JERSEY: Oct. 2013 - Governor vetos bill to ban laser pointer sales over $1 \mathrm{~mW}$

- NEW YORK CITY: Laser pointer regulations

- NEW YORK STATE: Illegal to aim a laser at an aircraft, or its flight path

- OREGON: "Unlawful directing" of a laser pointer

- PUERTO RICO: Illegal to aim at aircraft or law enforcement officers

- SOUTH CAROLINA: No sales to, or possession by, minors

- SOUTH CAROLINA: Myrtle Beach restricts minors and misuse

- SOUTH CAROLINA: Old North Myrtle Beach ordinance as of September 172012

- SOUTH CAROLINA: New North Myrtle Beach ordinance of February 2013

- TENNESSEE: Aiming a laser pointer at a law enforcement officer or similar

- TEXAS: Law enforcement and aircraft illumination

- UTAH: Unlawful use of a laser pointer

- VIRGINIA: Interference with operation of aircraft

- VIRGINIA: Illegal to aim lasers at law enforcement officers

- VIRGINIA, city of Virginia Beach: Misdemeanor to aim into eyes

\section{Regulatory response outside the US}

Similar regulatory reaction to the issue of misuse of hand held lasers has occurred in many countries. Here are some examples, taken from the web site Laserpointersafety.com

\section{EUROPEAN UNION: Call for EU-wide restrictions on laser pointers}

On November 3 2010, radiation safety authorities in Finland, Iceland, Norway and Sweden asked the European Commission to "immediately begin preparing a European Directive for battery-powered lasers and establish import restrictions on such items." The goal is to allow only Class 1 and 2 pointers; lasers above $1 \mathrm{~mW}$ would be restricted.

\section{AUSTRALIA: Advisory Circular - Lasers and Aircraft}

The Australian Government's Civil Aviation Safety Authority in April 2007 issued Advisory Circular AC 139-23(0), "Laser Emissions Which May Endanger the Safety of Aircraft". This "provides general information and advice on measures to protect pilots of civil aircraft from accidental laser beam strikes, on or in the vicinity of an aerodrome."

Another document, "Summary of Responses," lists the comments received during the draft period for AC 139-23(0) (e.g., before it was officially published). The comments and responses give additional insight into the document and laser hazard mitigation.

\section{CANADA: Criminal Code provisions}

Under the Criminal Code of Canada, someone who points a laser at an aircraft could be charged with a number of different sections, depending upon the circumstances. Some of these sections carry significant penalties, up to and including life imprisonment. These criminal charges could be laid in addition to the sections under the Aeronautics Act and Canadian Aviation Regulations.

\section{NORWAY: Possession and use regulated}

As of 1 Jan 2011, possession and use of laser pointers 5 milliwatts and above is restricted by the Norwegian Radiation Protection Authority.

\section{SWEDEN: Possession and use regulated}

The Swedish Radiation Protection Authority's Regulations on Lasers, updated in 2008, bans the possession or use of lasers over 5 milliwatts in public space. The relevant document is the "SSMFS 2008:14". The Swedish language document is Strålsäkerhetsmyndighetens föreskrifter om lasrar. 


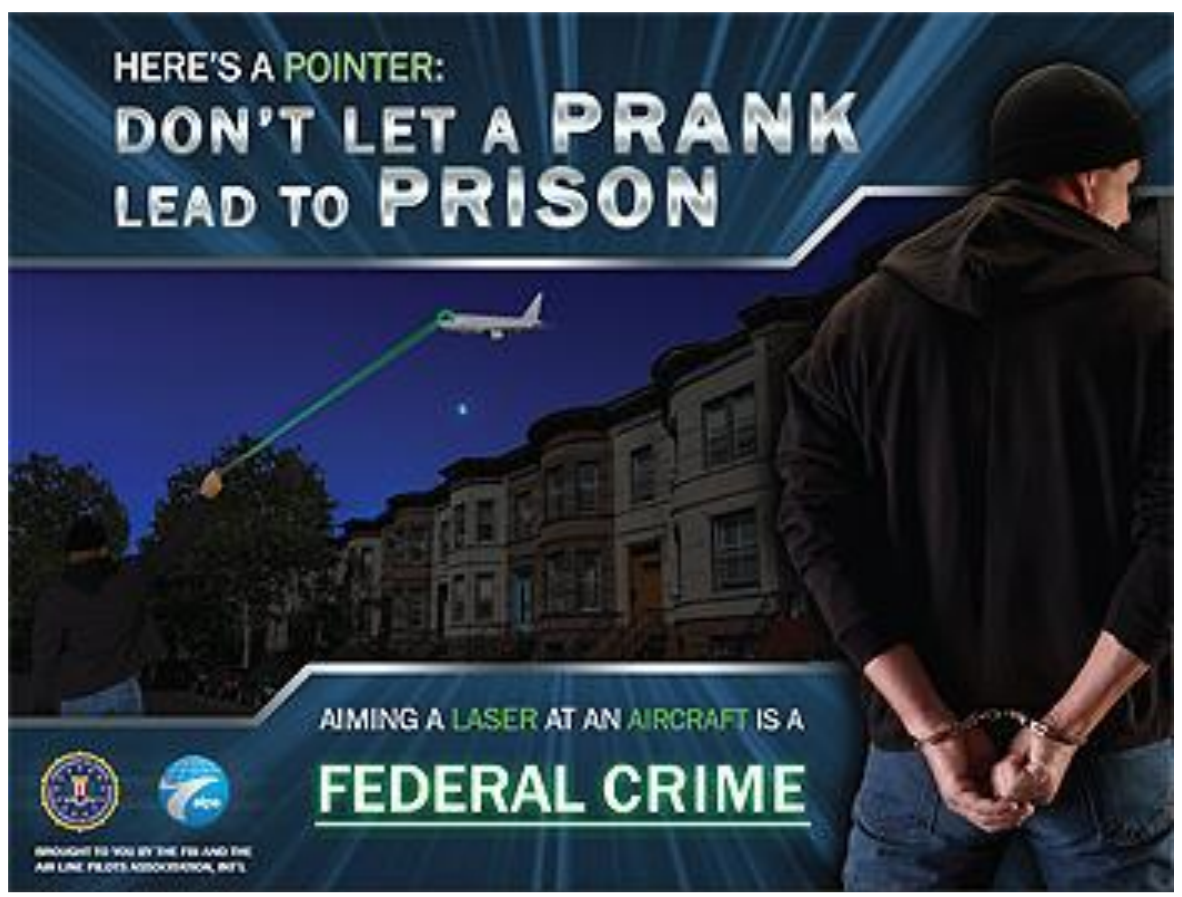

Figure 2. Billboard poster posted in a select number of US cities, Times Square, NY as an example.

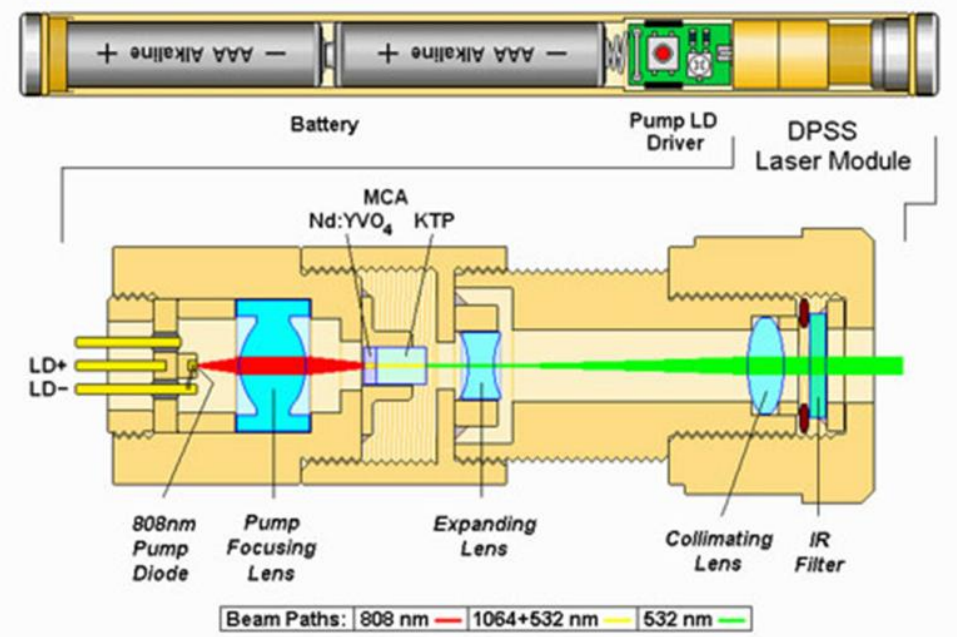

Figure 3. Internal view of Green laser pointer design

\section{What can we do?}

I think it is clear that illumination of aircraft is not a recommended practice, but what can we do about it? As in many practices that seem harmless but are not, education is the key, getting the word out. Speaking up when one observes inappropriate action will make all the difference. It is believed that the overwhelming number of people who engage in this activity are not trying to cause harm or injury but rather see it as a harmless activity with no consequences. It is the role of presentations like this one to inform and demonstrate that illuminating an aircraft is not harmless. 


\section{References \& Resources}

[1] Lasersafety.com

[2] K. Barat presentations to local HPS \& IEEE chapters “Aircraft Illumination" 2014,2015

[3] LSO Workshop, 2014, DOE Laser Safety Working Group

Proc. of SPIE Vol. 9793 97931P-7

Downloaded From: https://www.spiedigitallibrary.org/conference-proceedings-of-spie on 26 Apr 2023 Terms of Use: https://www.spiedigitallibrary.org/terms-of-use 